tions in association with Bergmann he prepared in I918 the penta-( $m$-digalloyl)-derivatives of $\alpha$ - and $\beta$-glucose, and found them to be indistinguishable from the principle of Chinese tannin excepting for a slight dirference in optical activity.

Fischer is entitled to a high place amongst the notable figures in chenical history associated with problems arising from the structure of uric acid and its derivatives. This work, begun in 1881 , when he resolved caffeine into methylcarbamide and dimethylalloxan, reached its climax in 1898 , when he derived purine from uric acid by means of indirect deoxidation. It has now passed into the text-books, and the classification of all such. materials, many of which are important products of animal and vegetable metabolism, is based on his notation of 1897 .

In view of their extent and the far-reaching biochemical conclusions based upon them, the labours of Fischer in the region of proteins make the same appeal to the imagination and evoke the same delight in craftsmanship as his activities amongst carbohydrates. Recognising amino-acids as the building materials of albuminoid molecules, he devised an unrivalled practical method for isolating them from the complex mixtures which follow the hydrolytic disruption of the proteins. Accumulating a large number of such units in their optically active forms, he pro ceeded to reassemble them as anhydrides, and thus elaborated molecules which, although much simpler than natural proteins, nevertheless approach them in physical properties. These were called polypeptides, and one of them, an octadecapeptide described in 1907 , attained a molecular weight of 1213. The experimental methods developed in the course of these investigations are too complex for summary description, but they represent an extraordinary technical feat, and establish a connecting link between laboratory svntheses and the peptones arising from incomplete disruption of protein molecules. The investigation is limited only by material considerations, for a calculation made by Fischer in I9I6 showed that the octadecapeptide has 816 possible isomerides, whilst a polypeptide involving thirty amino-acid molecules differing widely, but not entirely, amongst themselves mav have isomerides reaching $\mathrm{I} \cdot 28 \times 10^{27}$ in number.

Throughout these inquiries Fischer made frequent and skilful use of enzymes, developing a technique which will offer substantial guidance to later investigators of vital changes. In r 804 , having assembled a variety of artificial carbohydrates, he studied their behaviour towards different families of yeast, drawing the fundamental conclusion that the fermentative enzyme is an asymmetric agent attacking only those molecules of which the configuration does not differ too widely from that of $d$-glucose. Applving this principle to the natural and artificial $d$-glurosides, he ranged these in two groups, the a-d-glucosides being hvdrolvsed bv maltase and in different towards emulsin, the $\beta-d$-glucosides exhibiting converse behaviour. The l-glucosides, $d$-galactosides, arabinosides, xvlosides, rhamnosides, and glucoheptosides were not affected by either enzyme, and the glucosidic relation of sucrose, maltose, and lactose was determined by similar means. It was the knowledge thus gained which led Fischer to represent enzyme-action by the analogy of a lock-and-key, and to conclude that disaccharides are fermented only as a consequence of preliminary hydrolysis. Turning his attention to secretions of animal origin (1896), he studied the behaviour of carbohydrates and glucosides. towards a great variety of tissue extracts and juices, but it was when these were applied by him, in association with Abderhalden (1903), to the proteins and polypeptides that the most fruitful results arose, from which it followed very clearly that the synthetic polypeptides are susceptible to zymolysis only when constructed of those amino-acids which occur in the natural proteins themselves.

Although the subjects to which Fischer mainly devoted his attention were not related directly to problems of manufacture, he quickly made contact with the chemical industry, and many of the processes in use at the Bayer, Höchst, and Böhringer factories were based upon principles developed in his labora. tory; the improvement which he effected in the production of diethylbarbituric acid led to this compound becoming one of the most valuable hypnotics in pharmacy under the name "veronal." Whilst shunning publicity in its grosser forms, he played an active part in the German chemical world, and the reliance placed on his judgment by leaders of the German chemical industry ultimately grew into an attitude of trust which was quite exceptional. It was this which enabled him to become instrumental in establishing the Kaiser-Wilhelm-Institut für Chemie, a research foundation independent of teaching duties inaugurated in I912. A pronounced individualist, he trusted personalities more than organisations and wisdom more than learning, his own kindling personality and clear wisdom being freely applied to the furtherance of scientific method, both industrial and academic.

It is not difficult to imagine the demands which were made upon him during the war period, the five years which were destined to be his last. In a directive capacity he was associated with many of the commissions charged with solving chemical problems connected with the great conflict, but it was the food shortage which engrossed his attention most urgently. There is no doubt that these labours and their fruitless issue preyed too heavily upon a constitution undermined by lifelong over-application to exhausting labour, and in view of the great age attained by his father, who passed the ninety-fourth year, his own demise was premature in every sense.

Even when due allowance has been made for the storehouse of accumulated facts upon which the chemists of his era were empowered to draw and for the variety of technique which was at their com. mand, it can scarcely be claimed that in wealth of revelation and manipulative skill Emil Fischer is eclipsed by any of his predecessors. It is difficult to imagine that he can be surpassed by any of his successors. but whether this be so or not, his achievement will remain for all time a monument of industry, a masterpice of symmetry, and a gospel of inspiration.

\title{
The Physics and Chemistry of Colloids and their Bearing on Industrial Questions.
}

THE Faraday and Physical Societies held a joint discussion on "The Physics and Chemistry of Colloids and their Bearing on Industrial Questions" on October 25 in the spacious lecture theatre of the Institution of Mechanical Engineers. The societies were extremely fortunate in having the subject introduced by Prof. Theodor Svedberg, of the University of No. 2662 , VOL. IO6]
Upsala, who gave an excellent résumé, mainly from the physical point of view, of the present state of knowledge of the subject of colloids on the theoretical side. Prof. Svedberg's written contribution included an excellent bibliography of the subject, which will be found most helpful to physicists and others who wish to become acquainted with modern theoretical. 
developments. The ensuing discussion was divided into the following tive sections: (I) "Limulsions and Emulsincation," opened by Prol. F. G. Donnan; (2) "Ine r'nysical L'roperties of Elastic Giels, " upened by Mr. E. Hatschek and Pror. 11. K. Pructer (3) "Glass and Pyrosols," opened by Dir l1erbert Jackson; (4) "Non-aqueous Systems," opened by Sir Robert Robertson; and (5) "L'recipitation in Disperse Systems : Cataphoresis and Electro-endosmuse." opened by Prof. A. W. Porter.

In section (I) the discussion centred mainly around the important problem of the reversal of phases in emulsions produced by electrolytes. The results of experiments on soap emulsions carried out by $\mathrm{Mr}$. $\mathrm{S}$. S. Bhatnagar at University College, London, were given by the author, who concluded that there was a strict parallel between the reversal of phases in emulsions and the precipitation of suspensions by electrolytes. Apart from the considerable theoretical interest attachings to the subject, the matter is of practical importance in that it is clusely associated with the action of soaps as protective colloids, to which property it appears probable their detergent nature is due. The speakers were unanimous in affirming the efficiency of the electrical method, first suggested by Clayton (Brit. Assoc. Colloid Reports, No. 2, p. II4, IgI8), of ascertdining the point at which phase reversal takes place. A matter of considerable importance referred to by Prof. W. C. McC. Lewis, and agreed to by other speakers, was the necessity when studying the effects of electrolytes on colloids of employing solutions possessing the same conductivity rather than those of identical molar concentrations.

The discussion on the physical properties of elastic sels revealed how scanty is the present state of our knowledge of the mechanism of gel formation and the importance of further research in this direction. Mr. Hatschick emphasised the importance of an extended study of the mechanical properties of gels, which hitherto had been confined prectically to gelatin, in which chemical complications may arise. A much more promising field presented itself in non-aquevus svstems, e.g. vulcanised rubber in benzene. In an investigation into the mechanical properties of gelatin Mr. Hatschek had obtained the astonishing result that, after straining a rectangular prism of 10 per cent. gelatin gel for five days, not only had the stress practically disappeared, so that on removing the constraint the strain remained, but the optical anisotropy remained after removal of the stress.

Prof. Procter, in advocating his well-known solidsolution theory-which, he explained, differed from the sponge-like structure theory mainly on the question of size-pointed out that the difference was not unimportant, since microscopic size of network excludes or complicates the simple chemical causes which are sufficient for the solid-solution view. The opposite view involves a mechanical structure which itself demands explanation. Critics of the solidsolution theory, however, found it difficult to believe that a I per cent. agar gel is a solid solution, and Prof. Procter admitted that the case of agar presented great difficulties.

Some very important work relating to gel structure has been carried out in the laboratories of Prof. McBain at Bristol on soap solutions, which in Prof. McBain's opinion excludes the cellular-structure theory. It has been shown in his laboratory that a half-normal solution of sodium oleate could be made to exist in any one of three forms : (a) Transparent liquid (sol), (b) a jelly (gel), and $(c)$ a curd. The sol and gel are absolutely identical in everv respect except in mechanical properties. They display identity of No. 2662 , VOL. IO6]
$\mathrm{Na}$-ion content, refractive index, osmotic pressure, and conductivity, so that it appears that the particles present are identical in the sol and gel. On the contrary, in the curd form some of the soap separates out into fibrils and the conductivity disappears, this process being analogous to crystallisation. Prof. McBain considered these results to bear out the view of Zsigmondy and others that the particles in both sol and gel exist in micellar form and are linked together in some way analogous to the structure of liquid crystals. An example: of the extraordinary character of the sol-gel transformation was brough to notice by Prof. Svedberg. A non-aqueous gel was formed of cadmium in alcohol having a cadmium concentration of only 0.1 per cent., in which the slightest vibration was sufficient to break down the whole structure and change it to the sol state.

Sir Herbert Jackson, in opening up the subject of glass and pyrosols, expressed doubt, except perhaps in some cases of colouring, as to whether glass came within the domain of colloids. With goud glasses ordinary methods of illumination failed to reveal the Tyndall phenomenon, this being visible only with very strong illumination. The figures obtained by etching glasses he considered to be merely surface-tension effects, and afforded no evidence whatever of the colloidal nature of glass. In regard to the colouring of glasses much research is needed into the conditions under which various colours are produced Evidence was adduced by Sir Herbert which makes it appear probable that the colouring substances have specific effects, although pure diffraction effects depending on the sizes of particles undoubtedly exist.

Non-aqueous colloid systems were dealt with under three headings: (a) Nitro-cellulose, (b) Celluloid, and (c) Rubber. Sir Robert Robertson dealt with the colloidal properties of nitro-cellulose gelatinised by means of suitable solvents, which properties have an important bearing on the manufacture of propellants. Useful relationships had been established between the viscosities of solutions of cellulose, those of the result. ing solutions of nitro-cellulose, and the mechanical properties of the final dried material. $\mathrm{Br}$ controlling the viscosities of the solutions the required mechanical properties of the resultant dried nitrocellulose mixtures were assured. In connection with celluloid the discussion centred largely around the solvent property of binary mixtures, such as etheralcohol, which is very different from that of the constituents separately. The ether-alcohol complex theory originally put forward by Baker was largely criticised. The discussion on the colloidal properties of rubber was confined practically to a communica. tion by Mr. B. D. Porritt, who, in describing the effects of light on rubber, emphasised the important part played in rubber deterioration by oxvgen, both as a catalvst and by direct chemical action. The inclusion of a dye to absorb ultra-violet light helps to prevent the deterioration. Experiments on the sol-gel transformation produced in rubber solutions by light and oxygen tvere described.

Perhaps the most important paper of the whole discussion, in that it represented a distinct advance in theory, was that by $\mathrm{Mr}$. J. N. Mukherjee in section (5). Starting with the view that the charge on a suspensoid particle is due to adsorption, arising from chemical forces, of the ion the particle has in common with the peptising or stabilising elec. trolvte. Mr. Mukheriee has deduced a relation between the "electrical adsorbability "of the oppositely charged ion of the precinitating electrolyte and its valency and mobility. This theory not only results in the same series of cations arranged in order of adsorb- 
ability as that for the precipitation of negatively charged suspensoids, but also agrees extremely well with the most trustworthy experimental results on electro-endosmose.

On the whole, it may be said that the discussion centred around the physical properties of colloids rather than around their industrial applications, which are complex. Advancement in our knowledge of colloids can be made only by simplifying experimental conditions as much as possible, and thence building up step by step to the more complex cases. The full report of the discussion will be published in due course by the Department of Scientific and Industrial Research, and should be read by all those who are interested in this fascinating subject.

\section{University and Educational Intelligence.}

Bristol.-At Congregation held on October 22 the honorary degree of M.A. was conferred on Mr. Avery Adams, who has held the office of secretary to the Bristol Education Committee for thirty-three vears; Mr, G. H. Burkhardt, head of the North Wilts Secondary School and Technical Institution; and $\mathrm{Mr}$. W. A. Knight, head of Sexey's School at Bruton, Somerset.

Cambridge.-The trustees of the Capt. Scott Memorial Polar Research Trust have offered the University a sum of $6000 l$. towards the provision of a suitable wing or annexe to a proposed new school of geography, the special wing to serve as a Polar research institute. There is a prospect of financial heip towards the maintenance and upkeep of the institute from the same source. The institute is to act as a centre both for information on Polar matters and for the working up of results, and it is to include a Polar library, a museum of Polar equipment, a collection of biological and geological specimens, and a set of rooms for research work. Cambridge University is chosen for the site of the institute as a centre which has already proved itself friendly to such research; it contains a nucleus of Polar men able to use and take a keen interest in the department, and is likely to continue to produce men equipped with the necessary knowledge and spirit for further work in Polar regions. An appeal will shortly be issued for funds to endow the larger building required for geographical studies.

A committee at Cambridge has collected a fund to commemorate Sir Tames Frazer's great services to learning. It is proposed to endow a Frazer lectureship in social anthropologv, the lecture to be given annually in rotation at Oxford, Cambridge, Glasgow, and Liverpool.

It is proposed to make Dr. Duckworth. of Jesus College, reader in human anatomy. Dr. T. J. I'A. Bromwich, of St. John's College, has been re-appointed University lecturer in mathematics. Prof. I. T. Wilson has been elected a fellow of St. John's College.

The vote on the nroposed statute admitting women to.membership of the University has been fixed for December 8.

Major David Davies, M.P., has given $12,500 l$, to found a chair of tuberculosis at the Welsh National Medical School, University of Wales.

Four free lectures on "Four Great Geometers" (Archimedes, Galileo, Newton, and Clerk Maxwell) are announced for delivery by $\mathrm{Mr}$. W. D. Eggar at Gresham Colleoe, Basinghall Street, E.C.2, on November I6-19. The lecture hour is 6 o'clock.

THE sum of $425,000 l$. has been stated by $\mathrm{Mr}$. H. A. L. Fisher, President of the Board of EducaNO. 2662, VOL. IO6] tion, in reply to a question in Parliament, to be the price which the Duke of Bedford and his trustees have agreed to accept for the Bloomsbury site offered by the Government to the Senate of the University of London.

Notice is given by the University of London of the award in I92 I of the rool. Rogers prize, the subject for which is "Hyperthyroidism and its Surgical Treatment." Copies of the regulations governing the competition and information as to the date on which the essays must be received can be obtained from the Academic Registrar, University of London, South Kensington, S.W.7.

Viscount Haldane will deliver an address entitled "The Nationalisation of Universities" at a reunion of old students of the Royal College of Science on Tuesday next, November 9, at the Imperial College Union, Prince Consort Road, South Kensington, London, S.W.7. The president of the Old Students Association, Sir Richard Gregory, will take the chair at 8 p.m. The address will be followed by discussion.

THE prospectus of the courses to be held at the Municipal College of Technology, Manchester, during the year 1920-2I has been issued. Full-time courses extending over three years, which lead to certificates and degrees, are provided in mechanical, electrical, and sanitary engineering, and in the chemical and textile industries. Another feature of the college is the provision of part-time day courses for engineers' and other apprentices whose employers allow them to devote one whole day per week to study. Part-time evening courses which extend over five years are also given for the purpose of training men for responsible posts in industrial affairs. Research and advanced study receive attention, and students are prepared in part-time classes for degrees at Manchester and part-time in natural and technological sciences. A new degree of Doctor of Philosophy has been instituted with the object of encouraging research; candidates for this degree must be graduates of a university who have pursued an approved course of advanced study or research in Manchester University for a period of at least two years, of which not more than one year may be spent in another approved institution. Details of the full-time courses are given, but for particulars of the part-time classes application should be made to the Registrar for the prospectus of the department concerned.

ON September 29 the executive of the Engineering Training Association met, by authority of the council Training Association mider the transference of the work of the association to the Federation of British Indusof the association to the Engineering and National Employers'Federations. Representatives of these different bodies were present, and outlined the motives which induced their respective organisations to make the induced their respective or banalf of the Engineering and National Employers' Federations, stated that the chief reason for his society's offer was the increasing chief reason for his society's importance of training questions rvhich occur in the agenda of the federaquestions which occur Labour. Until now they had been satisfied with the work of the Engineering Training Association, but they felt that as the latter body was about to cease to be an independent unit thev were in the best position to carry on its work without interfering with that of other organisations. Mr. Prescott, speaking for the Federation of British Industries, said that they were prepared to carry on the work of the Engineering Training Association if they were asked to do so, or to stand aside if they felt satisfied that the work would be done properly by someone else The co-ordination of industrial educa- 